\title{
Baclofen Pseudopsychosis: Case Report
}

\author{
C. W. Roy, MB., Ch.B., M.R.C.P. (U.K.) D.R.C.O.G., I. R. Wakefield,
} BSc., M.R.C.S., L.R.C.P., M.B. B.S.

Rehabilitation Studies Unit, Princess Margaret Rose Orthopaedic Hospital, Fairmilehead, Edinburgh, EH10 7ED, Scotland.

\section{Summary}

Sudden withdrawal of baclofen has been shown to provoke hallucinations. There has been no documented case showing hallucinations persisting during treatment over several years and responsive to subsequent reductions in dosage.

Such a case is now reported. The chronicity of the symptoms originally suggested a psychotic illness, but this proved to be incorrect.

The literature on baclofen toxicity is reviewed.

Key words: Baclofen; drug toxicity; hallucinations; pseudopsychosis.

\section{Introduction}

Involuntary muscle spasms often pose a significant problem in patients with spinal paralysis, and reduction of these benefits both the patient and his attendants (Anonymous, 1977). Baclofen ('Lioresal'), a gamma-amino butyric acid derivative is regarded by many as the drug of choice for this condition (Terrence and Fromm, 1981). It is normally effective and well tolerated but adverse effects are not uncommon, especially when higher doses are used (Australian Drug Evaluation Committee, 1976). In particular, baclofen is known to exacerbate pre-existing psychoses, and visual hallucinations have been reported on sudden withdrawal of treatment (Lees, Clarke and Harrison, 1977(i); Stien, 1977; Terrence and Fromm, 1977). Hallucinations developing during treatment have also been reported, although rarely (Hachen and Krucker, 1977). To our knowledge, there have not been any documented cases where, over a prolonged period, dose-dependent relationships between the drug and hallucinations have been clearly established.

A case is now reported where a patient experienced hallucinations which were associated with continued baclofen therapy in high dosage. 


\section{Case report}

A thirty-seven year old man developed sudden C6 tetraplegia in January 1975 secondary to a presumed anterior spinal artery thrombosis. The only past medical history was L5/S1 laminectomy in 1961 for disc prolapse. There was no past history or family history of psychiatric disorder. He had a stable personality and good work record.

After sequential muscle transfers in both arms, he achieved wheelchair independence. Subsequent medical problems included bilateral hydronephrosis and hydroureter, renal abscess formation, ischial skin ulceration, epididymoorchitis, upper gastro-intestinal haemorrhage and notably flexor spasms for which a variety of anti-spastic agents were used, including baclofen. This drug was first started in May 1975 at a dosage of $20 \mathrm{mg}$ three times a day.

In May 1980, he became septicaemic from a renal abscess, which required drainage. During this episode he exhibited auditory and visual hallucinations which persisted after discharge. At this point his medication was baclofen 20 $\mathrm{mg}$ four times a day and trimethoprim $100 \mathrm{mg}$ nocte. Electroencephalography (EEG) in December 1980 was normal but in May 1981 suggested a focus in the right posterior temporal region with $1 \frac{1}{2} \mathrm{~Hz}$ moderate to high amplitude delta disturbance. During that month an association between the auditory hallucinations and the prescription of doses of baclofen at the top of the therapeutic range was suspected. The dose of this drug was reduced to $60 \mathrm{mg}$ per day, with a reduction in the frequency and severity of hallucinations, although this medication was not stopped at this stage.

The hallucinations were transiently abolished by chlorpromazine on one occasion, but subsequently recurred and persisted despite further anti-psychotic treatment with chlorpromazine, clopixol, thioridazine or trifluoperazine. During a further severe urinary tract infection in January 1982 the patient suffered grand mal convulsions, and phenytoin was started. E.E.G. was consistent with post-ictal changes or an encephalopathic disorder, but later that year was within normal limits.

Distressing muscle spasms subsequently prompted an increase in the dosage of baclofen to $20 \mathrm{mg}$ four times a day. Auditory hallucinations became a more severe problem and he also admitted to hearing his thoughts repeated aloud immediately after their occurrence-the syndrome of 'echo de pense'. Advice was obtained from three psychiatrists; each concluded that he was not schizophrenic in view of the absence of other diagnostic features such as thought blocking or ideas of passivity. The balance of opinion favoured a derealisation/ depersonalisation syndrome. Apart from baclofen, his other medication was orphenadrine $50 \mathrm{mg}$ tds, chlorpromazine $20 \mathrm{mg}$ bd, phenytoin $200 \mathrm{mg}$ nocte and temazepam $20 \mathrm{mg}$ nocte at that time. Hallucinations continued unabated but generally did not distress the patient.

Later, in July 1983, he experienced a further bout of septicaemia with grand mal seizures, choreiform movements of the arms, confusion, echopraxia, echolalia, olfactory hallucinations and exacerbation of the auditory hallucinations.

An intracranial space-occupying lesion was considered, but the EEG was normal and computed tomography only showed mild cerebral atrophy. A renal source 
for the infection was therefore presumed and he was treated empirically with gentamicin, cefotaxime and thioridazine. During this period baclofen, phenytoin and orphenadrine were inadvertently omitted from his therapeutic regime and the hallucinations disappeared. The patient had only one further brief episode of auditory hallucinations five days later.

Baclofen was never given to this man again. He suffered no subsequent episodes of visual, auditory or olfactory hallucinations. Spasticity continued to be a major problem, but he declined further treatment for this. He continued taking thioridazine $100 \mathrm{mg}$ a day and phenytoin $300 \mathrm{mg}$ nocte. He died in March 1985 during a grand mal convulsion. Post mortem examination was not performed.

\section{Discussion}

Although a number of methods are available to treat spasticity (Griffiths, 1985), the most commonly used long-term measure is oral drug therapy. Diazepam, baclofen and dantrolene are all in regular use, but the pharmacological effects and sites of action of these drugs differ; diazepam works centrally and at the spinal cord, baclofen at spinal level and dantrolene diminishes the force of intrafusal and extrafusal muscle fibre contractions (Davidoff, 1985; Hudgson and Weightmann, 1971).

Formerly the maximum dose of baclofen recommended for use outside hospital was $60 \mathrm{mg}$ per day (Australian Drug Evaluation Committee, 1976), but many patients require larger doses and $100 \mathrm{mg}$ per day is now accepted (Jones, 1985). After initiation of therapy in hospital, continuation of higher doses is normally well tolerated (Jones and Lance, 1976).

Our patient required treatment for spasticity in view of difficulties in nursing him when spasms were uncontrolled. However, auditory and visual hallucinations were associated with doses of $80 \mathrm{mg}$ per day or more, with symptoms lessening on reduction of dosage, and disappearing on withdrawal. Baclofen is known to be excreted by the kidneys, and the impairment of renal function leads to accumulation of the drug (Seyfert, Kraft, and Wagner, 1981). This man had temporary elevations of blood urea during intercurrent illnesses, but there was no evidence of renal impairment between these episodes. Hallucinations, however, persisted, suggesting that drug accumulation was not a causative factor.

Hallucinations can occur in a number of organic processes such as infection or temporal lobe epilepsy (Lishman, 1978). Our patient's hallucinations were not confined to episodes of infection, and indeed, disappeared during one septicaemic illness. He did suffer grand mal convulsions, and on occasion, had an abnormal EEG. The EEG findings, however, may not have been related to epilepsy since baclofen has been implicated in the production of abnormal EEGs with prominent delta wave activity (Seyfert, Kraft, and Wagner, 1981). Organic lesions that might cause epilepsy and hallucinations, such as temporal lobe abscess, were excluded as far as possible by computed tomography.

Echo de pense is normally considered to be a symptom of particular value in the diagnosis of schizophrenia (Gelder, Gath and Mayou, 1983) and this had to be considered as a cause of hallucinations in our patient. However, the absence of other features of schizophrenia, and the subsequent progress when not on baclofen, makes this diagnosis very unlikely. 
In view of the clear relationship between higher dosage of baclofen and hallucinations over a long period of time, followed by absence of hallucinations when the drug was withdrawn (with follow-up of 21 months), we suggest that baclofen at high dosage precipitated the hallucinations. A pre-disposition to hallucinations, however, cannot be excluded. The consistent reproduction of specific side effects of baclofen at a given dosage level accords with previous work (Jones and Lance, 1976).

The mechanism by which baclofen produces hallucinosis is not clear. Skausig and Korsgaard (1977) suggested a disturbance of dopamine metabolism based on their experience in Parkinsonian patients, but this view was challenged by Lees, Clarke and Harrison $(1977$, ii) who suggested an interaction with substance P.

This report shows that baclofen at high dosage may precipitate serious psychiatric phenomena mimicking a psychotic illness.

\section{Acknowledgements}

We wish to thank Professor Cairns Aitken for permission to report this patient, and thank him, Dr J. A. A. Hunter and Dr B. Pentland for their valuable comments. We are grateful to CIBA Laboratories for their helpful correspondence. This report could not have been completed without the secretarial assistance of Miss Angela Cowan, to whom we are grateful.

\section{References}

ANONYMOUS 1977 Baclofen in spasticity. Lancet, (ii):594-595.

Australian Drug Evaluation Committee 1976 Statement by the Chairman of the Australian Drug Evaluation Committee on the use of Baclofen. Medical Journal of Australia, i:322.

DAvidOFF RA 1985 Antispasticity drugs: mechanisms of action. Annals of Neurology, 17:107-116.

Gelder M, Gath D, Mayou R et al. 1983 Oxford Textbook of Psychiatry: Oxford University Press, Oxford, pp. 231-245.

GRIFfiths E 1985 Surgical approaches to spasticity. Paraplegia, 23:319.

HACHEN HJ, KRUCKER V 1977 Clinical and Laboratory Assessment of the Efficacy of Baclofen (Lioresal) on Urethral Sphincter Spasticity in Patients with Traumatic Paraplegia. European Urology, 3:237-240.

Hudgson P, Weightmann D 1971 Baclofen in the treatment of spasticity. British Medical Journal, 4:15-17.

JONES RF 1985 Lioresal: a fifteen year report. Paraplegia, 23:320.

JONES RF, LANCE JW 1976 Baclofen (Lioresal) in the long term management of spasticity. Medical Journal of Australia, i:654-657.

Lees AJ, Clarke CRA, Harrison MJ 1977 (i) Hallucinations after withdrawal of baclofen. Lancet, i:858.

Lees AJ, Clarke CRA, HaRrison MJ 1977 (ii) Hallucinations after sudden withdrawal of baclofen. Lancet, ii:45.

Lishman JA 1978 Organic Psychiatry: Blackwell Scientific Publications, Oxford, pp. 16 and 313.

SEYfert S, KRAFT D, WAGNER K 1981 Baclofen Dose in Haemodialysis and Renal Insufficiency. Nervenarzt, 52:616-617.

SKaUSIG OB, KorSGAARd S 1977 Hallucinations and Baclofen. Lancet, 1:1258.

STIEN R 1977 Hallucinations after sudden withdrawal of baclofen. Lancet, ii:44-45.

TERRENCE CF, Fromm GH 1981 Complications of baclofen withdrawal. Archives of Neurology, 38:588-589. 